\title{
A Biochemical Study of Human Skin Collagen and the Relation between Intra- and Intermolecular Cross-Linking *
}

\author{
Paul Bornstein † and Karl A. Piez \\ (From the Section on Protein Chemistry, Laboratory of Biochemistry, National Institute of \\ Dental Research, Bethesda, $M d$.)
}

Studies of collagen from experimental animals have led to a considerable understanding of the biological function and mode of biosynthesis of this important connective tissue protein $(2,3)$. The amino acid composition and sequence of collagen $(3,4)$, the helical structure of the triplestranded collagen monomer $(4,5)$, and the relationship between collagen and gelatin (4) have also been subjects of intensive investigation. Soluble collagen, when denatured by heat to break secondary bonds, has been shown to exist mainly in the form of $\alpha$ (single-chain)- and $\beta$ (doublechain)-components $(6-8)$. There is evidence indicating that two of the chains $(\alpha 1)$ comprising the collagen monomer are identical in amino acid composition whereas the third $(\alpha 2)$ is different (9-11). ${ }^{1}$ Although a number of linkages have been proposed (4), the nature of the covalent bonds involved in the intramolecular cross-linking of collagen and the relationship, if any, of such bonds to intermolecular cross-links have not been conclusively established.

Although distinct species differences in collagen chemistry have been demonstrated, it is reasonable to expect that much of the information obtained from the examination of other mammalian collagens will have direct relevance to the study of the protein in humans. However, the precise ap-

\footnotetext{
* Submitted for publication April 21, 1964 ; accepted May 15, 1964

Presented in part at the Forty-eighth Annual Meeting of the Federation of American Societies for Experimental Biology, April 1964. A portion of this work has been published in preliminary form (1).

† Research Associate, National Institutes of Health.

1 The previously described $\beta$-components $(8,11)$ are designated $\beta_{11}$ for $\alpha 1-\alpha 1$ and $\beta_{12}$ for $\alpha 1-\alpha 2$. The two $\alpha 1$ chains are assumed to be identical, since this fraction appears homogeneous. Direct evidence, however, is lacking on this point.
}

plication of such information to the elucidation of the possible role of altered collagen in certain pathological conditions must await the study of collagen chemistry in normal subjects. The need for careful base-line studies has prompted us to subject human collagen to some of the same procedures used to elucidate the structure of other mammalian collagens. In addition, since disturbances in the cross-linking process may play a role in some of the disorders of connective tissue, an attempt has been made to study certain aspects of the intra- and intermolecular covalent bonding of collagen and thus the relation of the collagen monomer to the polymeric forms in which it largely exists in tissues.

\section{Materials and Methods}

a) Source and preparation of collagen. The collagen used in this study was extracted from a sample of $32.5 \mathrm{~g}$ of skin (wet weight of cleaned skin) obtained from the back and abdomen of an infant who had died 36 hours after birth because of a cardiac malformation (single ventricle) incompatible with extrauterine life. The pregnancy was reported to have been normal, and no other pathological findings of note, with the exception of those resulting from the cardiac dysfunction, were encountered. Weight at birth was $2,600 \mathrm{~g}$.

Neutral salt-extracted collagen. The subcutaneous fat and epidermis were carefully removed with a scalpel, and the corium was ground to a coarse mince with a mechanical grinder. All procedures were performed at $5^{\circ} \mathrm{C}$. After washing with distilled water, the tissue was extracted for 48 hours with constant stirring in 650 $\mathrm{ml}$ of $1 \mathrm{M} \mathrm{NaCl}$ in $0.02 \mathrm{M}$ Tris buffer at $\mathrm{pH} \mathrm{7.4}$. The residue was removed by filtering through several layers of cheesecloth and the supernatant liquid further clarified by filtration through a Celite filter cake on a Buchner funnel. Solid $\mathrm{NaCl}$ was added to the supernatant fluid to a final concentration of $20 \%$ and the solution allowed to stand for 30 to 60 minutes until precipitation of collagen was complete. The collagen was removed by centrifugation at $13,000 \times g$ for 20 minutes. Sufficient distilled water was added to redissolve the collagen, and 
precipitation with $\mathrm{NaCl}$ was repeated. After redissolving the precipitate by reducing the salt concentration to 1 to $2 \%$ with distilled water, the collagen was precipitated a third time by lowering the $\mathrm{pH}$ to 4.0 with a small quantity of acetic acid. The precipitate was removed by centrifugation and dissolved in $0.5 \mathrm{M}$ acetic acid. After exhaustive dialysis against distilled water the collagen was lyophilized and stored over $\mathrm{CaCl}_{2}$ at $5^{\circ} \mathrm{C}$.

Acid-extracted collagen. The residue obtained after extraction with $1 \mathrm{M} \mathrm{NaCl}$ was washed with distilled water and suspended in $650 \mathrm{ml}$ of $0.5 \mathrm{M}$ acetic acid. Extraction was carried out for 48 hours with constant stirring. After filtration, collagen was precipitated by the addition of $\mathrm{NaCl}$ to a concentration of $10 \%$. The precipitate was separated by centrifugation and dissolved by the addition of distilled water and exhaustive dialysis against $0.15 \mathrm{M}$ acetic acid. The collagen solution was lyophilized and the dry salt-free protein stored as above. Acetic acid extraction was repeated a total of five times. The quantity of collagen obtained during each of the last three extractions was too small to permit its characterization by lyophilization and chromatography on carboxymethylcellulose. Hydroxyproline determinations (12) were performed on these extracts.

Guanidine-extracted collagen. The tissue remaining after sequential extraction with salt and acetic acid was suspended in $500 \mathrm{ml}$ of $5 \mathrm{M}$ guanidine, ${ }^{2}$ which had been neutralized to $\mathrm{pH} 7.5$ with $\mathrm{NaOH}$ and clarified with activated charcoal. Extraction was carried out with stirring for 72 hours. After filtration the filtrate was dialyzed exhaustively against distilled water to insure removal of all guanidine. The remaining protein, which had largely precipitated, was lyophilized as a suspension and stored. Extraction with guanidine was repeated a second time with $250 \mathrm{ml}$ of $5 \mathrm{M}$ guanidine.

b) Chromatography on carboxymethylcellulose. A weighed quantity of dry collagen, usually 50 to $100 \mathrm{mg}$, was suspended in 20 to $30 \mathrm{ml}$ of starting buffer, 0.06 ionic strength $\mathrm{Na}$ acetate, $\mathrm{pH} 4.8$, and stirred overnight at $5^{\circ} \mathrm{C}$. The sample was denatured by warming to $40^{\circ}$ $\mathrm{C}$ for 30 minutes and any insoluble material removed by centrifugation or filtration. The method of chromatography was essentially that of Piez, Eigner, and Lewis (11). Carboxymethylcellulose ${ }^{3}$ was equilibrated with starting buffer and poured under pressure into a jacketed $2.5-\times 20-\mathrm{cm}$ column, maintained at $40^{\circ} \mathrm{C}$. The sample was applied to the column with a finger pump (Sigma motor) and elution started. A linear gradient was obtained by utilizing a constant level two-chamber device with $410 \mathrm{ml}$ of $\mathrm{Na}$ acetate buffer, 0.06 ionic strength, $\mathrm{pH}$ 4.8 , in one chamber and an equal weight of limiting buffer, 0.06 ionic strength $\mathrm{Na}$ acetate and $0.1 \mathrm{M} \mathrm{NaCl}, \mathrm{pH}$ 4.8 , in the other. The optical density of the effluent at $230 \mathrm{~m} \mu$ was monitored continually by the use of a flow cell (1-cm light path, $0.07-\mathrm{ml}$ volume) in a Beckman DB

\footnotetext{
${ }^{2}$ Guanidine $\mathrm{HCl}$ obtained from Eastman Organic Chemicals, Kingsport, Tenn.

3 Lot no. 109798 , exchange capacity, $0.59 \mathrm{mEq}$ per $\mathrm{g}$, Bio-Rad Laboratories, Richmond, Calif.
}

spectrophotometer. A simultaneous recording was obtained by the use of a Sargent SRL chart recorder with logarithmic gears run at a speed of 3 inches per hour. Ten-ml fractions were collected. Elution was carried out at a flow rate of $120 \mathrm{ml}$ per hour. All buffers were prewarmed and deaerated to avoid the formation of air bubbles in the system. At the conclusion of a run the column was washed for 30 minutes with a solution $0.01 \mathrm{~N}$ in $\mathrm{NaOH}$ and $0.5 \mathrm{~N}$ in $\mathrm{NaCl}$, followed by starting buffer until a stable base line was achieved.

Rechromatography was performed in essentially the same manner as described above. Protein fractions were dialyzed in the cold against starting buffer and then warmed to $40^{\circ} \mathrm{C}$ before being pumped on the column. When large volumes of sample were involved, the flow rate was increased to $250 \mathrm{ml}$ per hour and reduced to $120 \mathrm{ml}$ per hour at the start of the gradient.

Protein fractions were separated from buffer salts by passage through a column of Sephadex G-25 equilibrated with a pyridine acetate buffer, $\mathrm{pH} 4.4(4.0 \mathrm{ml}$ pyridine and $6.7 \mathrm{ml}$ acetic acid per $\mathrm{L}$ ). The volatile nature of this buffer permitted the preparation of dry saltfree collagen by lyophilization.

c) Amino acid analysis. Three $\mathrm{mg}$ of collagen or one of its components was hydrolyzed in $6 \mathrm{~N} \mathrm{HCl}$ under nitrogen at $108^{\circ} \mathrm{C}$ for 24 hours. The acid was removed by distillation under reduced pressure at $60^{\circ} \mathrm{C}$ and the residue dissolved in distilled water. A sample representing about $1 \mathrm{mg}$ of protein was analyzed on an automatic amino acid analyzer utilizing a column of Dowex $50 \times 12$ resin (13). Appropriate corrections were made for loss of the labile amino acids, threonine, serine, tyrosine, and methionine, and for incomplete release of valine (8). All analyses were performed in duplicate and the results averaged.

d) Ultracentrifugation. Lyophilized $\alpha$ - and $\beta$-components of collagen, separated and purified by chromatography, were dissolved in $0.15 \mathrm{M}$ potassium acetate, $\mathrm{pH}$ 4.8 , by warming to $40^{\circ} \mathrm{C}$. Sedimentation velocity patterns were obtained by centrifugation in $12-\mathrm{mm}$ standard and wedge window cells at $40^{\circ} \mathrm{C}$ and 59,780 rpm in a Spinco model $\mathrm{E}$ ultracentrifuge employing Schlieren optics. Protein concentrations were obtained by measuring areas under sedimentation curves, this method having been standardized by polarimetry (see below) and Kjeldahl nitrogen determinations. Sedimentation coefficients at $40^{\circ} \mathrm{C}$ in buffer were derived by conventional calculations and corrected to zero concentration at $20^{\circ} \mathrm{C}$ in water.

The molecular weights of $\alpha 1$ and $\beta_{12}$ were measured by the method of sedimentation equilibrium as described by Richards and Schachman (14) and adapted to collagen components by Lewis and Piez (15). The Spinco model E ultracentrifuge was used with Rayleigh optics. The molecular weight of $\alpha 1$ was determined in $0.15 \mathrm{M}$ potassium acetate, $\mathrm{pH} 4.8$, at $40^{\circ} \mathrm{C}$; that of $\beta_{12}$ in $5 \mathrm{M}$ guanidine, $\mathrm{pH} 7.5$, at $6^{\circ} \mathrm{C}$. After extensive dialysis against buffer, the concentrations of the collagen solutions were determined as a function of the number of 
TABLE I

Collagen obtained by sequential extraction of $32.5 \mathrm{~g}$ of human (infant) skin with salt, acid, and guanidine solutions

\begin{tabular}{|c|c|c|}
\hline Solvent & $\begin{array}{l}\text { Quantity of } \\
\text { collagen } \\
\text { extracted }\end{array}$ & $\begin{array}{l}\% \beta \text {-com- } \\
\text { ponent }\end{array}$ \\
\hline & $m g$ & $\%$ \\
\hline $\begin{array}{l}650 \mathrm{ml} 1 \mathrm{M} \mathrm{NaCl} \text { in } 0.02 \mathrm{M} \text { Tris, } \\
\text { pH } 7.4\end{array}$ & 33 & 32 \\
\hline $650 \mathrm{ml} 0.5 \mathrm{M}$ acetic acid & 232 & 61 \\
\hline $500 \mathrm{ml} 0.5 \mathrm{M}$ acetic acid & 150 & 67 \\
\hline $250 \mathrm{ml} 0.5 \mathrm{M}$ acetic acid & $16 *$ & $\dagger$ \\
\hline $250 \mathrm{ml} 0.5 \mathrm{M}$ acetic acid & $16^{*}$ & $t$ \\
\hline $250 \mathrm{ml} 0.5 \mathrm{M}$ acetic acid & 9* & $\dagger$ \\
\hline $500 \mathrm{ml} 5 \mathrm{M}$ guanidine & $860 \ddagger$ & 74 \\
\hline $250 \mathrm{ml} 5 \mathrm{M}$ guanidine & $95 \ddagger$ & 78 \\
\hline Total & 1,4118 & \\
\hline
\end{tabular}

* Calculated from hydroxyproline determinations.

+ Not determined.

¥ Corrected for noncollagenous impurities by hydroxyproline determinations.

$\S$ This represents $23 \%$ of the total collagen present in the sample [based on the data of Clausen (17) assuming a water content of $65 \%$ for skin]. ...

interference fringes measured in a double sector synthetic boundary cell of the capillary type. Equilibrium studies with six dilutions of each component were performed, and 1.8-mm liquid columns with a false bottom of FC-43 were employed. The equilibrium speed for $\alpha 1$ was $6,995 \mathrm{rpm}$; that for $\mathrm{B}_{12}$ was $8,225 \mathrm{rpm}$. Rayleigh patterns were measured in a Nikon comparator and molecular weights calculated as described by Richards and Schachman (14). The partial specific volume was taken to be 0.705 (15). Computations were performed with the aid of a Minneapolis Honeywell 805 computer.

e) Polarimetry. Optical rotation was measured in a Rudolph photoelectric spectropolarimeter equipped with a monochromator and an oscillating polarizer. Samples of acid-extracted collagen were dissolved in cold $0.15 \mathrm{M}$ potassium acetate, $\mathrm{pH} 4.8$, and dialyzed at $5^{\circ} \mathrm{C}$ against a large volume of the same buffer for 24 hours. Shortly before use samples were clarified by centrifugation at $5^{\circ} \mathrm{C}$ and $100,000 \times g$ in a Spinco model $\mathrm{L}$ centrifuge for 3 hours. Readings were taken in a 1-decimeter jacketed cell with a capacity of $2 \mathrm{ml}$. Temperature control to $\pm 0.05^{\circ} \mathrm{C}$ was provided by a circulating water bath. Melting curves were obtained by a stepwise increase in temperature. Each change was achieved within 5 minutes, and a total of 30 minutes was allowed for equilibration. Most measurements were made at the $313 \mathrm{~mm} \mathrm{Hg}$ line. The specific rotation at $589 \mathrm{~m} \mu$ was measured with a zirconium light source. Protein concentrations were determined by the use of a microKjeldahl method, a nitrogen content of $18.6 \%$ being assumed for collagen.

f) Viscometry. Viscosity measurements were made at $15^{\circ} \mathrm{C}$ in a coiled capillary viscometer with a flow rate of about 50 seconds for water. Samples of acid-extracted collagen were dissolved in cold $0.15 \mathrm{M}$ potassium acetate,
$\mathrm{pH} 4.8$, and dialyzed at $5^{\circ} \mathrm{C}$ against a large quantity of the same buffer. Solutions were clarified shortly before use by centrifugation in the cold at $100,000 \times g$. Nitrogen concentrations were measured by the micro-Kjeldahl technique.

Acrylamide gel electrophoresis. Acrylamide gel electrophoresis was performed according to the method of Nagai, Gross, and Piez (16). This technique, which utilizes a polymerized acrylamide gel, permits the diagnostic separation of $\alpha$ - and $\beta$-components in very small samples of soluble collagen (of the order of $100 \mu \mathrm{g}$ ).

\section{Results}

Extractability of collagen. Although precautions were not taken to achieve completely quantitative recoveries, some idea of the relative quantities of collagen extractable by salt, acid, and guanidine may be obtained by reference to Table I. It can be seen that after exhaustive extraction with salt and acetic acid solutions, the use of guanidine resulted in the solubilization of a quantity of collagen that far exceeded the total previously extracted. Similar increases in yield have

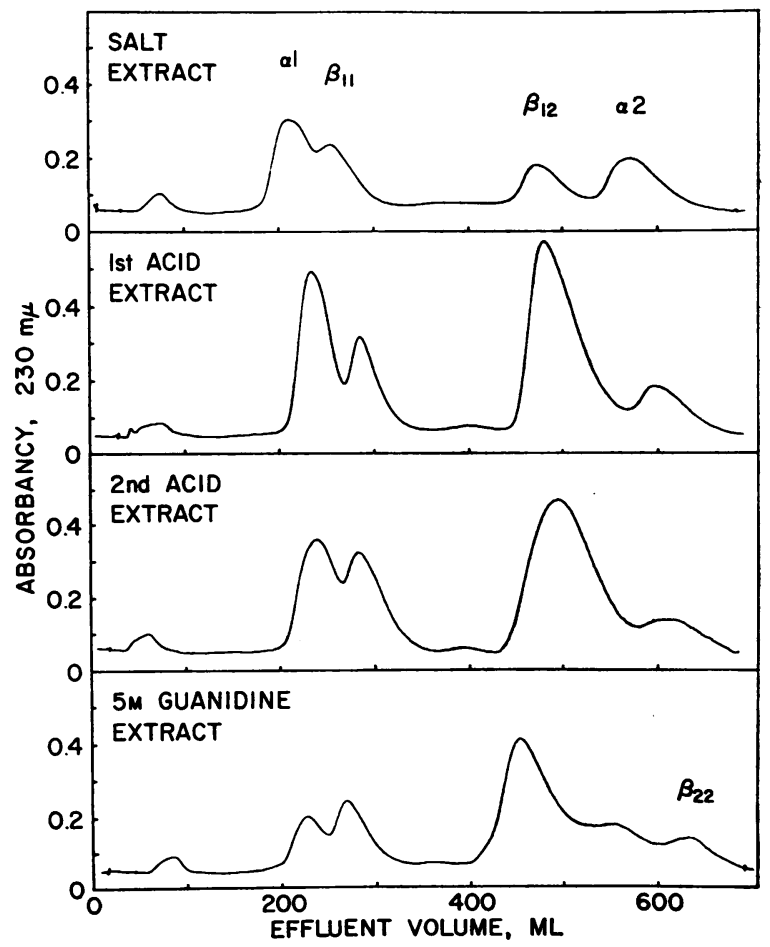

Fig. 1. Elution Patrerns of SAlt-, ACID-, AND gUANIDINE-EXTRACTED COLlagens. Chromatography performed on carboxymethylcellulose at $40^{\circ} \mathrm{C}$. A linear gradient of ionic strength varying from 0.06 to 0.16 , at a constant $\mathrm{pH}$ of 4.8 , was employed. 


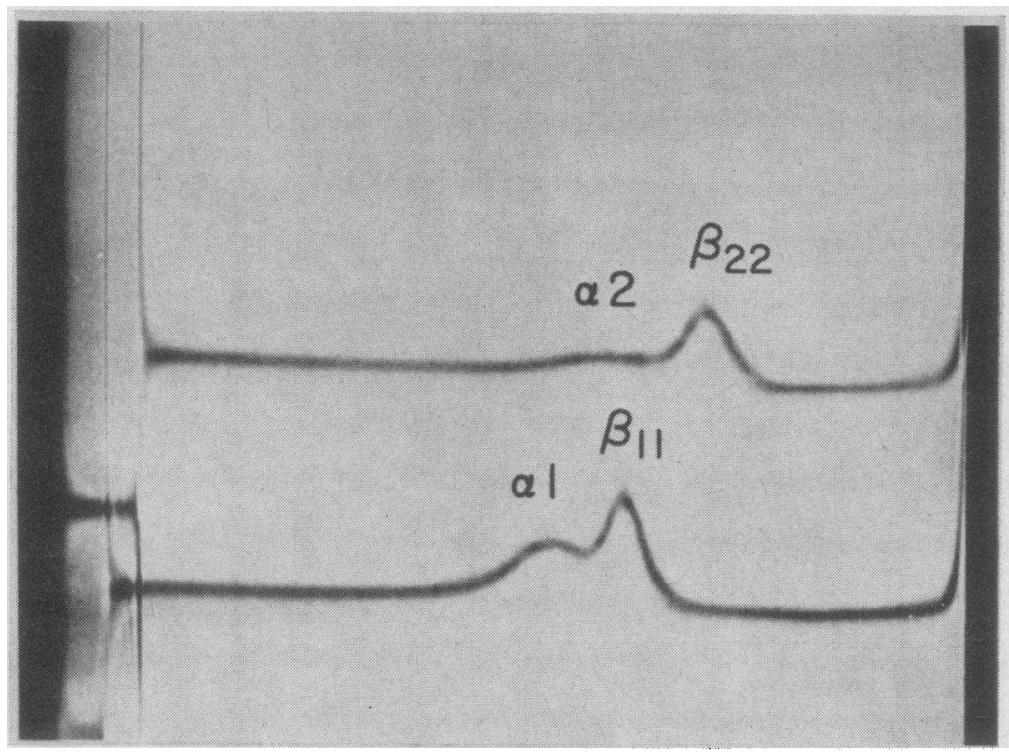

Fig. 2. Sedimentation pattern of Purified $\beta_{22}$ (upper pattern, wedge window cell). A sample of $\beta_{11}$ purified to a lesser degree (lower pattern, standard cell) is included for comparison. Centrifugation performed in $12-\mathrm{mm}$ cells at $59,780 \mathrm{rpm}$ in $0.15 \mathrm{M}$ potassium acetate, $\mathrm{pH} 4.8$, at $40^{\circ} \mathrm{C}$; phase plate angle $70^{\circ}$, sedimentation from left to right, exposure at 106 minutes. The relative quantities of $\alpha$-components are exaggerated due to the effect described by Johnston and Ogston (19).

been observed in the extraction of collagen from the skins of growing rats and guinea pigs (18). The $\alpha$ - and $\beta$-components derived from guanidineand acid-extracted collagens, respectively, are identical in their behavior on carboxymethylcellulose column chromatography and acrylamide gel electrophoresis, and in their amino acid composition, indicating that covalent bonds are not disrupted during the course of guanidine extraction.

Chromatography on carboxymethylcellulose. Representative chromatograms of salt-, acid-, and guanidine-extracted collagen are illustrated in Figure 1. The elution patterns resemble those obtained with collagens from rat tail tendon and skin, carp swim bladder, and dogfish shark skin (11). It is apparent that the proportion of double chain $\beta$-components increases as the extracting solvent changes from salt to acid to guanidine, indicating that the latter solvent is most effective in extracting cross-linked material. The percentage of $\beta$-components in the extracted collagens was estimated by planimetry of areas under the curves in elution patterns. The results are listed in Table I. $\beta$-Components and higher aggregates of collagen consistently accounted for more than two- thirds of the collagen in guanidine extracts. Since these estimates include only that fraction of collagen that could be eluted from carboxymethylcellulose, the percentage may be higher.

Lyophilized samples of salt- and acid-extracted collagens in general dissolved completely in the 0.06 ionic strength sodium acetate, $\mathrm{pH} 4.8$, used as starting buffer, and estimation of the total protein eluted from the column during the course of chromatography indicated that 90 to $95 \%$ of the protein placed on the column could be eluted with the gradient system used. Guanidine-extracted collagen was less easily redissolved in starting buffer. In one experiment $27 \%$ of the lyophilized protein failed to dissolve. However, $60 \%$ of the residue proved to be noncollagenous by hydroxyproline measurement. Since hydroxyproline assay indicated that the starting material was only $75 \%$ collagen, apparently much of the noncollagenous material was excluded from the column by its insolubility in the starting buffer, whereas the soluble fraction should, by exclusion, consist almost entirely of collagen. Measurement of protein eluted after the soluble fraction was placed on carboxymethylcellulose revealed that 
only $54 \%$ of the material was recovered. The soluble collagen that failed to be eluted probably consisted of high molecular weight aggregates resulting from the ability of guanidine to extract intermolecularly cross-linked collagen (see Discussion).

The identification of $\beta_{22}$. Chromatograms of guanidine-extracted collagen consistently revealed a small peak after $\alpha 2$ in the effluent of the carboxymethylcellulose column (Figure 1). A peak in this region had not previously been detected in the chromatography of other collagens extracted by the usual techniques. However, its presence was subsequently noted in chromatograms of rat and guinea pig collagens extracted with $5 \mathrm{M}$ guanidine (18).

The protein contained in the chromatographic fractions represented by this peak was purified by rechromatography. The purified protein was examined in the ultracentrifuge (Figure 2) and was found to consist largely of a single component. The small amount of slower sedimenting material is exaggerated in size as a result of the anomaly first described by Johnston and Ogston (19) and is estimated to represent about $10 \%$ of the total protein. For comparison a sample of $\beta_{11}$ purified to a lesser degree from contamination with $\alpha 1$ is included in the double cell Schlieren pattern. The calculated value for the sedimentation constant of the protein in question agrees closely with values obtained for $\beta_{12}$ and $\beta_{11}$ (see below). The mobility of this material on acrylamide gel electrophoresis was found to be identical with that of the $\beta_{12}$ and $\beta_{11}$ components of collagen. That this new $\beta$-component is a dimer of the $\alpha 2$ chain is indicated by the finding that its amino acid composition is identical to that of $\alpha 2$ (see below and Table II). Its chromatographic behavior is consistent with this structure in that it has the same position in the effluent relative to $\alpha 2$ that $\beta_{11}$ has to $\alpha 1$.

Amino acid analyses. The amino acid composition of human skin collagen and its $\alpha$ - and $\beta$-components are listed in Table II. The values for whole collagen are the average of two determinations performed on acetic acid-extracted collagen. The compositions of the $\alpha$ - and $\beta$-components were determined three or four times. The identity in composition, within the errors of measurement, of $\beta_{22}$ and $\alpha 2$, and of $\beta_{11}$ and $\alpha 1$ is apparent. The composition of $\beta_{12}$ is compatible with its structure as a dimer of $\alpha 1$ and $\alpha 2$, whereas the composition of whole collagen is in accord with the conclusion, previously derived from work with other vertebrate collagens (9-11), that the monomer consists of two $\alpha 1$ and one $\alpha 2$ chains.

The amino acid composition of human skin collagen and its components resembles the corresponding constituents of rat skin, although small but significant differences exist. Hence the alanine is somewhat higher in human collagen, whereas the methionine and isoleucine are somewhat lower. As in the rat, significant differences in the contents of 4-hydroxyproline, glutamic acid, proline, alanine, valine, isoleucine, leucine, hydroxylysine, lysine, and histidine may be found in comparing the $\alpha 1$ and $\alpha 2$ chains. Human skin $\alpha 1$ and $\alpha 2$ chains differ considerably in their tyrosine content, whereas this is not true in the rat. On the other hand, the rat $\alpha 2$ chain lacks 3-hydroxyproline, whereas both human $\alpha 1$ and $\alpha 2$ chains contain one residue of this amino acid per chain. ${ }^{4}$

Ultracentrifugational studies. The values for

TABLE II

Amino acid composition of human skin collagen and its constituent components

\begin{tabular}{|c|c|c|c|c|c|c|}
\hline & \multicolumn{6}{|c|}{ Residues/1,000 residues } \\
\hline & Collagen* & $\alpha 1$ & $\beta_{11}$ & $\beta_{12}$ & $\alpha 2$ & $\beta_{22}$ \\
\hline 3-Hydroxyproline & 1.1 & 0.8 & 1.0 & 1.0 & 0.9 & 1.0 \\
\hline 4-Hydroxyproline & 93 & 91 & 91 & 82 & 82 & 83 \\
\hline Aspartic acid & 45 & 43 & 43 & 46 & 47 & 48 \\
\hline Threonine & 17.5 & 16.5 & 16.3 & 17.9 & 19.2 & 19.3 \\
\hline Serine & 35.6 & 36.8 & 36.7 & 35.2 & 35.1 & 34.1 \\
\hline Glutamic acid & 73 & 77 & 76 & 72 & 68 & 68 \\
\hline Proline & 128 & 135 & 136 & 123 & 120 & 118 \\
\hline Glycine & 330 & 333 & 332 & 338 & 337 & 339 \\
\hline Alanine & 110 & 115 & 116 & 112 & 105 & 104 \\
\hline Valine & 24.4 & 20.5 & 20.6 & 28.8 & 33.3 & 31.1 \\
\hline Methionine & 6.2 & 4.9 & 5.0 & 5.0 & 5.2 & 5.4 \\
\hline Isoleucine & 9.5 & 6.6 & 6.5 & 11.6 & 14.8 & 13.7 \\
\hline Leucine & 24.3 & 19.5 & 19.1 & 26.1 & 30.1 & 30.7 \\
\hline Tyrosine & 2.8 & 2.1 & 2.0 & 3.8 & 4.6 & 4.6 \\
\hline Phenylalanine & 12.0 & 12.3 & 12.5 & 12.3 & 11.7 & 12.2 \\
\hline Hydroxylysine & 5.8 & 4.4 & 4.4 & 6.1 & 7.6 & 8.0 \\
\hline Amide nitrogen & $(36.9)$ & $(37.9)$ & $(37.2)$ & $(44)$ & $(45)$ & $(45)$ \\
\hline Lysine & 26.9 & 30.0 & 30.1 & 25.2 & 21.6 & 21.3 \\
\hline Histidine & 4.8 & 3.0 & 2.0 & 6.3 & 9.7 & 10.7 \\
\hline Arginine & 51 & 50 & 51 & 49 & 51 & 50 \\
\hline
\end{tabular}

* Extracted with acetic acid after neutral salt extraction (see Methods).

4 The mean residue weight of collagen is 91 . Since the $\alpha$ chains have a molecular weight of about 100,000 , there are about 1,100 residues per chain. 
TABLE III

Measured physical-chemical constant of a sample of human skin collagen and its constituent chains*

\begin{tabular}{lcrr}
\hline \hline & Collagen & $\alpha$ & $\beta$ \\
\hline Intrinsic viscosity & 16.6 deciliters $/ \mathrm{g}$ & & \\
Specific rotation & & & \\
$\quad[\alpha]_{313}$ & $-2,540^{\circ}$ & $-831^{\circ}$ \\
$\quad[\alpha]_{689}$ & $-428^{\circ}$ & $-142^{\circ}$ \\
Denaturation temperature & $38.5^{\circ} \mathrm{C}$ & & \\
Molecular weight & & 103,000 & 170,000 \\
Sedimentation coefficient, $\mathrm{S}^{\circ}{ }^{20, w}$ & & $3.0 \mathrm{~S}$ & $4.0 \mathrm{~S}$ \\
\hline
\end{tabular}

* All determinations with the exception of the molecular weight of the $\beta$-component were performed in $0.15 \mathrm{M}$ potassium acetate, $1 \mathrm{H} 4.8$ The latter determination was performed in $5 \mathrm{M}$ guanidine.

the reciprocal of the sedimentation coefficients for $\alpha$ - and $\beta$-components at several concentrations are plotted in Figure 3. Extrapolation to zero concentration and conversion to sedimentation coefficients at $20^{\circ} \mathrm{C}$ in water resulted in values of $3.0 \mathrm{~S}$ for the $\alpha$ chains and $4.0 \mathrm{~S}$ for the $\beta$-components (Table III). The present data are not sufficiently extensive to permit the calculation of a sedimentation coefficient for each individual chain. Extrapolation to zero concentration for both $\alpha$ - and $\beta$-components was based on the assumption that the sedimentation coefficients for $\alpha 1$ and $\alpha 2$, and for $\beta_{12}, \beta_{11}$, and $\beta_{22}$, if not identical, were reasonably similar. In more extensive experiments, values of $3.16 \mathrm{~S}$ and $3.08 \mathrm{~S}$ were obtained for rat skin collagen $\alpha 1$ and $\alpha 2$ chains (15). The small difference may be within experimental error. The value for rat skin collagen $B_{12}$ was found to be $4.20 \mathrm{~S}$.

Molecular weight determinations, using the technique of sedimentation equilibrium, were performed on samples of $\alpha 1$ and $B_{12}$. The results are listed in Table III. The value of 103,000 for $\alpha 1$ was obtained in potassium acetate buffer and agrees closely with that of 98,000 obtained for rat skin $\alpha 1$ by use of the same technique (15). Because $\beta$-components tend to degrade when kept at $40^{\circ} \mathrm{C}$ for the periods of time needed to achieve equilibrium (16 to 24 hours) and aggregate at lower temperatures, it was necessary to perform molecular weight determinations in $5 \mathrm{M}$ guanidine. With this technique, errors of measurement are considerably greater. The value of 170,000 is the result of a single determination and is within the experimental error of the value of 196,000 obtained in more extensive studies with rat skin $\beta_{12}$ (15).

Optical rotatory properties. The striking levorotation of native human skin collagen solutions is characteristic of solutions of this protein. Values for specific rotations similar to those listed in Table III have been found in studies of rat skin and calf skin collagen (4). The marked contribution

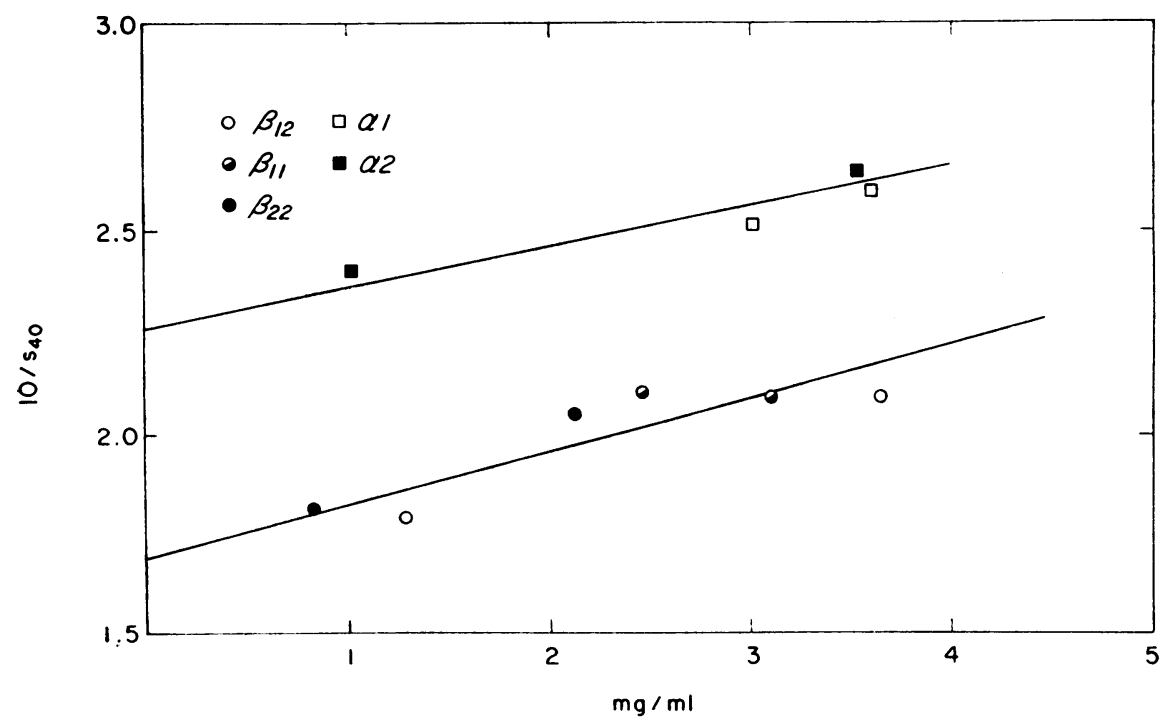

Fig. 3. Sedimentation coefficients of $\alpha$ - AND $\beta$-components plotted as a funcTION OF CONCENTRATION. The ordinate represents the reciprocal of coefficients determined at $40^{\circ} \mathrm{C}$ in $0.15 \mathrm{M}$ potassium acetate, $\mathrm{pH} 4.8$. The values for $\beta_{22}$ fall close to the straight line plot determined by values for all $\beta$-components. 
of the helical structure of collagen to its optical rotation can be seen in the finding that heat-denatured collagen or gelatin, in which chains exist as random coils, exhibits a specific rotation which approaches that of the mean residue rotation of the component amino acids. In Table III the specific rotation of gelatin is listed in the columns headed $\alpha$ and $\beta$.

Denaturation temperature. The collagen to gelatin transition or melting curve was determined by following the change in optical rotation that occurred when a dilute solution of native acid-extracted collagen was warmed in a stepwise fashion (Figure 4 ). $T_{M}$, or the temperature at the midpoint of transition, was found to be $38.5^{\circ} \mathrm{C}$, a value similar to that obtained for other mammalian collagens (4).

Viscometric studies. The intrinsic viscosity was determined by plotting the reduced viscosity $\left(\eta_{\mathrm{sp}} / \mathrm{C}\right)$ against concentration and extrapolating to zero concentration. Specific viscosities $\left[\eta_{\mathrm{sp}}=\left(\eta^{\prime}-\eta\right) / \eta\right.$, where $\eta^{\prime}$ is the viscosity of the protein solution and $\eta$ the viscosity of the solvent] were determined at several concentrations. The value of 16.6 deciliters ( $\mathrm{dl}$ ) per $\mathrm{g}$ obtained for the intrinsic viscosity of human skin collagen is in the range of 13 to $17 \mathrm{dl}$ per $\mathrm{g}$ obtained by a number of investigators for mammalian and fish collagens (4). The precise value of the intrinsic viscosity is influenced by the buffer used and by the degree of aggregation present in the preparation of collagen tested.

\section{Discussion}

The study of human collagen has been hampered by difficulty in obtaining material suitable for biochemical investigation. Bakerman (20) has studied the variation in yield of acid-extractable human skin collagen with age. His data indicate a maximum of 1.2 to $1.8 \mathrm{mg}$ of citric acid-soluble collagen per gram of skin in term fetuses, with a rapid decrease in extractable collagen with increasing age. Skin from individuals older than 15 years yielded less than $0.5 \mathrm{mg}$ per $\mathrm{g}$. In the present work a considerably larger quantity of collagen (11.8 mg per $\mathrm{g}$ skin) was extracted with dilute acetic acid from the skin of a young infant. The difference in extracting solvent, precise conditions, and inherent individual variation may

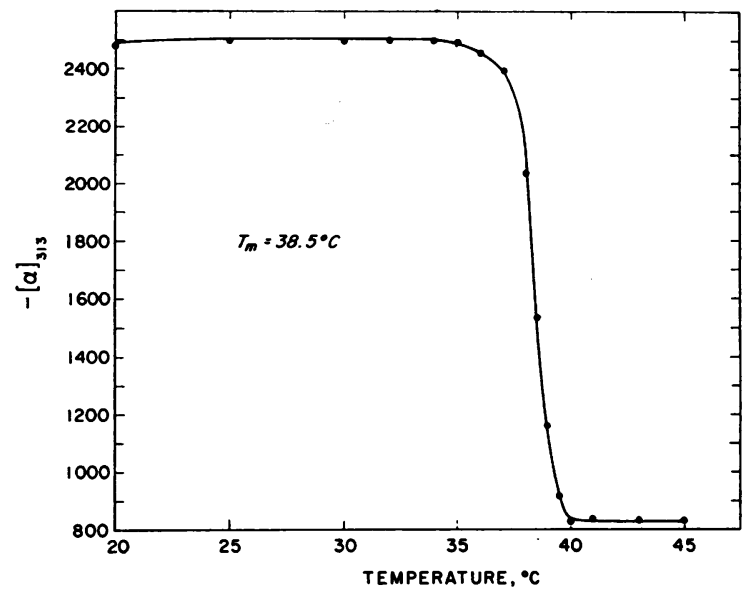

Fig. 4. Thermal denaturation curve of ACID-EXTRACTED SKIN COLLAGEN. $T_{M}$ represents the temperature at the midpoint of transition from the ordered helical structure of collagen to random coil gelation as followed by a change in optical rotation.

account for the difference in yield. The additional use of $5 \mathrm{M}$ guanidine resulted in a twofold increase in the collagen obtained. In other experiments, however, the yield of guanidine-extracted collagen from samples of skin of older individuals was significantly less than that obtained from infant skin. Such collagen did not chromatograph on carboxymethylcellulose under the conditions described in this work and may well exist in the form of highly cross-linked material. Since much of the pathological human material available for biochemical investigation is likely to be of this nature, the resolution of higher aggregates of collagen remains an important problem.

Eastoe in 1955 (21) determined the amino acid composition of human bone and Achilles tendon extracted as gelatin. The differences in the nature of the material examined as well as differences in techniques do not permit a precise comparison of results. However, the amino acid composition of a number of purified vertebrate collagens has now been studied, and in general they have been found to be similar, although speciesspecific differences exist. The composition of $\alpha$ and $\beta$-components from several species has also been studied in detail with findings analogous to those reported in this work (11).

It would be of interest to compare the amino acid composition of human collagen reported in this work with similar studies of other normal 
specimens. Minor amino acid substitutions might well occur in a protein like collagen, which exists largely in a repeating helical structure, without compromising its function. Such variation could complicate the detection of disorders of collagen structure in which a crucial amino acid substitution may have taken place. However, the effective comparison of normal collagens and collagens suspected of being abnormal must probably await the elaboration of smaller reproducible fragments of the collagen molecule, since the problems involved in performing precise comparative amino acid composition or sequence studies on structures of the size of $\alpha$ chains remain formidable.

The data obtained by ultracentrifugation, polarimetry, and viscometry closely parallel similar studies in the rat and confirm the similarities in molecular structure indicated by studies of amino acid composition. The relatively high denaturation temperature, $38.5^{\circ} \mathrm{C}$, is generally consistent with the high percentage of imino acids (222 residues per 1,000). Bakerman and Hersh (22), in referring to work that has appeared in abstract form, indicate a denaturation temperature of $36^{\circ}$ $\mathrm{C}$ for human skin collagen. These authors found an optical rotation of $-414^{\circ}$ at $589 \mathrm{~m} \mu$ and an intrinsic viscosity of $13.5 \mathrm{dl}$ per $\mathrm{g}$ for citric acidsoluble material. Boucek, Noble, Kao, and Elden (23) determined the intrinsic viscosity and sedimentation coefficients of acetic acid-extracted human collagen and attempted to derive its molecular weight from these data. Their values varied widely and differ considerably from the results of many investigators working with other collagens. Their use of unpurified collagen extracts may in part account for this discrepancy.

The use of solvents such as neutral salts and acidic buffers at $\mathrm{pH} 3$ to 5 has yielded extractable collagens from skin and other tissues whose precise relationship to the much larger insoluble fraction (as revealed by hydroxyproline determinations on the residue) has not been entirely clear. This is reflected in the use of a number of terms such as procollagen, tropocollagen, and neutral salt-extractable collagen to specify the conditions under which the collagen was obtained. Jackson and Bentley (24) on the basis of their experiments involving the incorporation of glycine- $\mathrm{C}^{14}$ into collagen, as well as their analysis of the results of other workers, have suggested that col- lagen exists as a spectrum of aggregrates of varying stabilities and that the nature of the collagen fraction extracted by any given solvent depends on its relative ability to dissociate these aggregates. The ease of extraction seemed to correlate inversely with the time elapsed since the constituent polypeptide chains had been synthesized. This concept has found some measure of support in studies in which acid-extracted collagen could be shown to contain a higher percentage of $\beta$-components (i.e., was more highly cross-linked) than did neutral salt-extractable collagen $(9,25)$. Orekhovich, Shpikiter, Kazakova, and Mazourov (26) and Martin, Piez, and Lewis (27) also demonstrated that glycine- $C^{14}$ was incorporated into $\alpha$ chains before it appeared in $\beta$-components.

While the process of intramolecular cross-linking has undergone considerable scrutiny and is understood in terms of $\alpha$ - and $\beta$-components, the manner in which this process may be extended to intermolecular cross-linking, as well as the nature of the covalent bonds involved, has not been determined. Indeed the concept of intermolecular covalent cross-linking has been based largely on reasoning deduced in part from the marked insolubility of a large proportion of collagen in tissues. Although the triple-chain covalently bonded $\gamma$-component identified by several investigators (28-31) could well arise entirely by intramolecular cross-linking, Veis, Anesey, and Cohen (32) have been able to demonstrate more highly aggregated species in fractions of bovine skin gelatin that could not be broken down to smaller fragments by heat or chemical denaturation and sedimented homogeneously in the ultracentrifuge. These presumably represent covalently linked polymers of the collagen monomer produced by a combination of intra- and intermolecular cross-linking.

The similarity of intra- and intermolecular covalent bonds in collagen is indirectly suggested by the work of Kuhn, Zimmer, Waykole, and Fietzek (33) and Gross (34). The former workers treated acid-insoluble bovine skin collagen with alkaline solutions and recovered a material resembling alkali-treated acid-extracted collagen on the basis of its sedimentation in the ultracentrifuge, change in optical rotation with heat, and ability to form specific aggregates on treatment with ATP. The experiments of Gross indicate that in experimental animals intermolecular as 
well as intramolecular cross-links (35) were affected by lathyrogens.

Although the identity of intra- and intermolecular bonds cannot be established until the chemical nature of these cross-links has been defined, the present work provides additional strong presumptive evidence for their similarity. It is now generally accepted that the triple-chain collagen monomer consists of two $\alpha 1$ chains and one $\alpha 2$ chain (9-11). $\quad \beta_{22}$, a dimer composed of two $\alpha 2$ chains, could therefore result only from the formation of an intermolecular bond. The similarity in behavior of $\beta_{22}$ to $\beta_{12}$ and $\beta_{11}$ in its elution from carboxymethylcellulose, in acrylamide gel electrophoresis, and in its sedimentation in the ultracentrifuge make it very likely that the three dimers are formed as part of the same process. The appearance of $\beta_{22}$ only in guanidine extracts is consistent with the concept that this dimer can occur only in intermolecularly bonded collagen. Neutral salt and acid solvents lack the ability to break hydrogen bonds in the cold and therefore extract a fraction of collagen that seems to be aggregated to a very limited degree. The denaturing action of guanidine, however, may enable this solvent to disaggregate those chains which, although an integral part of a complex polymeric structure, have yet to become completely insoluble as a result of multiple cross-links. The finding that guanidine-extracted collagen contains more $\beta$-components than the theoretical maximum of $67 \%$, which could be expected if only intramolecularly bonded collagen were solubilized, is consistent with this concept.

It has seemed reasonable to presume that the elaboration of higher aggregates of collagen and their orientation into fibrils involved the crosslinking of triple-chain units, the component chains having previously been covalently bonded. The demonstration, in guanidine extracts, of doublechain components that have resulted from the formation of intermolecular covalent bonds suggests, however, that intermolecularly bonded collagen may result in part from collagen monomers, some of whose component chains are not covalently linked. The recent finding from this laboratory (18) that glycine- $\mathrm{C}^{\mathbf{1 4}}$ is incorporated into the guanidine-extractable fraction of collagen pari passu with its incorporation into acetic acid-extractable collagen supports this hypothesis.
Although a $\gamma$-component could be demonstrated in guanidine extracts of human skin (1), it constituted only a small proportion of the collagen, and it too could have arisen from intermolecular bonding.

There is considerable speculation that the process of aging and some degenerative diseases of connective tissue may be associated with an increase in the degree of cross-linking in collagen. A change in the nature of the cross-links formed could also occur. Gustavson (36) and Milch (37) have pointed out the possibility that metabolic products such as acetaldehyde and other aldehydes may, with time, introduce new crosslinks in collagen, thus altering its physiologic properties. The experiments of Levene (38) and Veis and Drake (39) also indicate the importance of aldehydes in the cross-linking process. Milch (40), on the basis of in vitro experiments, has made the interesting suggestion that autoxidized polymerized homogentisic acid may be responsible for the degenerative joint disease found in association with alkaptonuria. The direct examination of the cross-linking groups as they exist in both normal and pathological tissues is therefore a matter of considerable importance.

\section{Summary}

1) Normal human skin collagen has been studied with regard to $a$ ) the amino acid composition of the collagen monomer and its component chains ; $b$ ) the separation, by carboxymethylcellulose chromatography, of the $\alpha$ (single chain)- and $\beta$ (double chain)- components from collagen fractions extracted with different solvents; $c$ ) the sedimentation coefficients and molecular weights of the $\alpha$ - and $\beta$-components; and $d$ ) the optical rotation, intrinsic viscosity, and denaturation temperature of acetic acid-extracted collagen. The results are largely similar to studies performed on other mammalian collagens, although small differences exist that reflect the 'unique structure of collagen in each species.

2) Collagen fractions extracted with neutral salt, acetic acid, and $5 \mathrm{M}$ guanidine were compared. The analysis of guanidine extracts revealed a higher percentage of $\beta$-components than could result from intramolecularly bonded collagen alone, and the presence of $\beta_{2 \xi}$, a dimer of $\alpha 2$, 
which according to present concepts can arise only from intermolecularly bonded collagen.

3) The extraction of intermolecularly bonded collagen by guanidine results in $\beta$-components that are indistinguishable by present criteria from those extracted with salt and dilute acid solutions. This observation, together with the finding that the $\beta_{22}$ double-chain component structurally resembles the $\beta_{12}$ and $\beta_{11}$ double-chain components formed as a result of intramolecular cross-linking, suggests that cross-linking in skin collagen is a single continuous process proceeding both intraand intermolecularly and progressing from the formation of double chains to highly aggregated polymers.

\section{References}

1. Bornstein, P., G. R. Martin, and K. A. Piez. Intermolecular cross-linking of collagen and the identification of a new $\beta$-component. Science 1964, 144, 1220.

2. Harkness, R. D. Biological functions of collagen. Biol. Rev. 1961, 36, 399.

3. Lowther, D. A. Chemical aspects of collagen fibrillogenesis in International Review of Connective Tissue Research, D. A. Hall, Ed. New York, Academic Press, 1963, vol. 1, p. 64.

4. Harrington, W. F., and P. H. Von Hippel. The structure of collagen and gelatin. Advanc. Protein Chem. 1961, 16, 1.

5. Ramachandran, G. N. Molecular structure of collagen in International Review of Connective Tissue Research, D. A. Hall, Ed. New York, Academic Press, 1963, vol. 1, p. 127.

6. Orekhovich, V. N., and V. O. Shpikiter. Study of some properties of denatured procollagen with an aid of the ultracentrifuge. Dokl. Akad. Nauk SSSR, Otd. Biokh. 1955, 101, 529.

7. Boedtker, H., and P. Doty. The native and denatured state of soluble collagen. J. Amer. chem. Soc. 1956, 78, 4267.

8. Piez, K. A., E. Weiss, and M. S. Lewis. The separation and characterization of the $\alpha$ - and $\beta$-components of calf skin collagen. J. biol. Chem. 1960, 235, 1987.

9. Piez, K. A., M. S. Lewis, G. R. Martin, and J. Gross. Subunits of the collagen molecule. Biochim. biophys. Acta (Amst.) 1961, 53, 596.

10. Schleyer, M. Trenning der $\alpha$ - und $\beta$-Komponenten aus Tropokollagen. Aminosäuresequenzen des Kollagens, V. Hoppe-Seylers Z. physiol. Chem. 1962, 329, 97.

11. Piez, K. A., E. A. Eigner, and M. S. Lewis. The chromatographic separation and amino acid composition of the subunits of several collagens. Biochemistry 1963, 2, 58.
12. Prockop, D. J., and S. Undenfriend. A specific method for the analysis of hydroxyproline in tissues and urine. Analyt. Biochem. 1960, 1, 228.

13. Piez, K. A., and L. Morris. A modified procedure for the automatic analysis of amino acids. Analyt. Biochem. 1960, 1, 187.

14. Richards, E. G., and H. K. Schachman. Ultracentrifuge studies with Rayleigh interference optics I. General applications. J. phys. Chem. 1959, 63, 1578.

15. Lewis, M. S., and K. A. Piez. Sedimentation equilibrium studies of the molecular weight of single and double chains from rat skin collagen. Biochemistry, in press.

16. Nagai, Y., J. Gross, and K. A. Piez. Disc electrophoresis of collagen components. Ann. N. Y. Acad. Sci., in press.

17. Clausen, B. Influence of age on connective tissue. Hexosamine and hydroxyproline in human aorta, myocardium, and skin. Lab. Invest. 1962, 11, 229.

18. Bornstein, P., and G. R. Martin. Unpublished observations.

19. Johnston, J. P., and A. G. Ogston. A boundary anomaly found in the ultracentrifugal sedimentation of mixtures. Trans. Faraday Soc. 1946, 42, 789.

20. Bakerman, S. Quantitative extraction of acid-soluble human skin collagen with age. Nature (Lond.) 1962, 196, 375.

21. Eastoe, J. E. The amino acid composition of mammalian collagen and gelatin. Biochem. J. 1955, $61,589$.

22. Bakerman, S., and R. T. Hersh. Extraction from human skin of soluble collagen molecules containing only beta components. Nature (Lond.) 1964, 201, 190.

23. Boucek, R. J., N. L. Noble, K.-Y. T. Kao, and H. R. Elden. The effects of age, sex, and race upon the acetic acid fractions of collagen (human biopsyconnective tissue). J. Geront. 1958, 13, 2.

24. Jackson, D. S., and J. P. Bentley. On the significance of the extractable collagens. J. biophys. biochem. Cytol. 1960, 7, 37.

25. Orekhovich, V. N., V. O. Shpikiter, V. I. Mazourov, and V. O. Kounina. Procollagens. Classification, metabolism, action of proteinases. Bull. Soc. Chim. biol. (Paris) 1960, 42, 505.

26. Orekhovich, V., V. Shpikiter, O. Kasakova, and V. Mazourov. The incorporation of $\mathrm{C}^{14}$-labeled glycine into the $\alpha$ - and $\beta$-components of procollagen. Arch. Biochem. 1959, 85, 554.

27. Martin, G. R., K. A. Piez, and M. S. Lewis. The incorporation of $\left[{ }^{14} \mathrm{C}\right]$ glycine into the subunits of collagens from normal and lathyritic animals. Biochim. biophys. Acta (Amst.) 1963, 69, 472.

28. Veis, A., and J. Cohen. Reversible transformation of gelatin to the collagen structure. Nature (Lond.) 1960, 186, 720. 
29. Rice, R. V. Reappearance of certain structural features of native collagen after thermal transformation. Proc. nat. Acad. Sci. (Wash.) 1960, 46, 1186.

30. Altgelt, K., A. J. Hodge, and F. O. Schmitt. Gamma tropocollagen: a reversibly denaturable collagen macromolecule. Proc. nat. Acad. Sci. (Wash.) 1961, 47, 1914.

31. Grassman, W., K. Hannig, and J. Engle. Das quantitative Verhaltnis zwischen $\alpha$ - und $\beta$-Komponente des denaturienten loslichen Kollagens in der Ultrazentrifuge sowie Beschreibung einer Schneller sedimentierenden $\boldsymbol{\gamma}$-Komponte. Hoppe-Seylers $Z$. physiol. Chem. 1961, 324, 284.

32. Veis, A., J. Anesey, and J. Cohen. The characterization of the $\boldsymbol{\gamma}$-component of gelatin. Arch. Biochem. 1962, 98, 104.

33. Kuhn, K., E. Zimmer, P. Waykole, and P. Fietzek. Die Wirkung von Alkali auf Kollagen. HoppeSeylers Z. physiol. Chem. 1963, 333, 209.
34. Gross, J. An intermolecular defect of collagen in experimental lathyrism. Biochim. biophys. Acta (Amst.) 1963, 74, 314

35. Martin, G. R., J. Gross, K. A. Piez, and M. S. Lewis. On the intramolecular cross-linking of collagen in lathyritic rats. Biochim. biophys. Acta (Amst.) 1961, 53, 599.

36. Gustavson, K. H. The Chemistry and Reactivity of Collagen. New York, Academic Press, 1956.

37. Milch, R. A. Studies of collagen tissue aging: interaction of certain intermediary metabolites with collagen. Gerontologia (Basel) 1963, 7, 129.

38. Levene, C. I. Studies on the mode of action of lathyrogenic compounds. J. exp. Med. 1962, 116, 119.

39. Veis, A., and M. P. Drake. The introduction of intramolecular covalent cross-linkages into ichthyocol tropocollagen with monofunctional aldehydes. J. biol. Chem. 1963, 238, 2003.

40. Milch, R. A. Biochemical studies on the pathogenesis of collagen tissue changes in alkaptonuria. Clin. Orthop. 1962, 24, 213. 